\title{
A frameshift variant of CYP2C8 was identified in a patient who suffered from rhabdomyolysis after administration of cerivastatin
}

Received: 14 June 2004 / Accepted: 16 July 2004/Published online: 9 September 2004

(C) The Japan Society of Human Genetics and Springer-Verlag 2004

\begin{abstract}
A hypercholesterolemic patient medicated with cerivastatin for 22 days resulted in acute rhabdomyolysis. CYP2C8 and CYP3A4 are the major enzymes responsible for the metabolism of cerivastatin, and a transporter, OATP2, contributes to uptake of cerivastatin to the liver. In this study, the patient's DNA was sequenced in order to identify a variant that would lead to the adverse effect of cerivastatin. Three nucleotide variants, 475delA, G874C, and T1551C, were found in the exons of CYP2C8. The patient was homozygous for $475 \mathrm{delA}$ variant that leads to frameshift and premature termination. Accordingly, the patient is most likely lacking the enzyme activity. The patient's children were both heterozygous for the mutation. The patient had three nucleotide variants in exon 4 (A388G) and exon 5 (C571T and C597T) of OATP2 that were all heterozygous. No nucleotide variation in the exons of CYP3A4 was identified. To our knowledge, this is the first report showing that the adverse effect of cerivastatin might be caused by the genetic variant of CYP2C8.
\end{abstract}

C. Ishikawa $\cdot$ S. Anjo

Department of Clinical Pharmaceutics, Faculty of Pharmaceutical Sciences,

Toho University, Chiba, Japan

H. Ozaki · K. Shirai

Internal Medicine, Sakura Hospital,

School of Medicine, Toho University,

Chiba, Japan

T. Nakajima $\cdot$ I. Inoue $(\bowtie)$

Division of Genetic Diagnosis,

The Institute of Medical Science,

The University of Tokyo, 4-6-1 Shirokanedai,

Minato-ku, Tokyo 108-8639, Japan

E-mail: ituro@ims.u-tokyo.ac.jp

Tel: + 81-3-54495325

Fax: + 81-3-54495764

T. Ishii $\cdot \mathrm{S}$. Kanai

Department of Pharmacy, Faculty of Medicine,

Sakura Hospital, Toho University, Chiba, Japan

\section{Introduction}

All hydroxymethylglutaryl-CoA reductase inhibitors (statins) potentially cause rhabdomyolysis as a serious adverse effect (Rossenson 2004). Cerivastatin was developed as a highly potent, lipophilic, and pure enantiomeric reductase inhibitor and has been evaluated in clinical efficacy and safety trials since 1993 (Stein 1998). Its dual mechanism of elimination mediated by CYP2C8 and CYP3A4 was originally thought to impart a safety benefit relative to other statins that were exclusively metabolized via the CYP3A4 pathway. However, despite the dual metabolizing pathways, cerivastatin caused rhabdomyolysis more frequently than other statins, especially when cerivastatin was given together with other drugs such as gemfibrozil (Farmer 2001; Staffa et al. 2002). In vitro experiment with human liver microsome demonstrated that gemfibrozil inhibited CYP2C8 activity leading to a decreased level of M-23 in the cerivastatin-metabolizing pathway, which at least partially explains the interaction between gemfibrozil and cerivastatin (Wang et al. 2002). Because of the adverse effects in the muscles causing rhabdomyolysis, cerivastatin was withdrawn from the market in August 2001. In the metabolic pathway of cerivastatin, CYP2C8 and CYP3A4 are equally important in the formation of $\mathrm{M}-1$ and the subsequent formation of M-23, the major metabolite of cerivastatin, is mainly mediated by CYP2C8 (Mück 2000). It was also suggested that transporters OATP2 and MPR2 contributed to hepatic clearance of cerivastatin (Matushima et al. 2002). In the present study, we sequenced the above candidate genes in the DNA of a patient who suffered from rhabdomyolysis after taking cerivastatin.

\section{Subjects and methods}

Subject A 74-year-old hypercholesterolemic woman who showed rhabdomyolysis after taking cerivastatin 
for 22 days, her son, and her daughter were recruited for the study. Serum creatinine phosphokinase was $19,190 \mathrm{IU} / 1$, and myoglobin level was over $3,000 \mathrm{ng} / \mathrm{ml}$. The participants gave informed consent, and the study was performed according to the Institutional Review Board of Toho University. The patient had taken pravastatin for the previous 2 years and simvastatin for 1.5 years before administration of cerivastatin, and no complaints with those drugs were reported. A consanguineous marriage was described for the patient's parents.

$P C R$ condition and primer design Puregene DNA isolation kit was used to isolate genomic DNA from peripheral blood (Gentra systems, Inc., Minneapolis, MN, USA). Taq DNA polymerase (EX Taq HS) was from Takara (Kyoto, Japan). PCR amplification was under the following conditions: $94^{\circ} \mathrm{C}$ for $1 \mathrm{~min}, 40$ cycles of $94^{\circ} \mathrm{C}$ for $30 \mathrm{~s}, 62^{\circ} \mathrm{C}$ for $30 \mathrm{~s}$, and $72^{\circ} \mathrm{C}$ for $1 \mathrm{~min}$, then $72^{\circ} \mathrm{C}$ for $5 \mathrm{~min}$. Primer sequences are shown in Table 1 . Nucleotide variations were searched with direct sequencing using BigDye Terminator cycle sequencing on an ABI PRISM 3700 DNA analyzer (Applied Biosystems, Tokyo, Japan).

\section{Results and discussion}

The hypercholesterolemic patient showed severe rhabdomyolysis after taking cerivastatin. Cerivastatin is uptaken and metabolized in liver by OATP2, CYP2C8, and CYP3A4. To clarify the genetic susceptibility to the adverse effect of cerivastatin, these candidate genes were analyzed by direct sequencing in the patient and her children.

Table 1 Primers used for sequencing CYP2C8, CYP3A4, and OATP2 exons

\begin{tabular}{|c|c|c|c|}
\hline Exon(s) & Forward primer $\left(5^{\prime}-3^{\prime}\right)^{\mathrm{a}}$ & Reverse primer $\left(5^{\prime}-3^{\prime}\right)^{\mathrm{a}}$ & $\begin{array}{l}\text { Product } \\
\text { size (bp) }\end{array}$ \\
\hline \multicolumn{4}{|l|}{ CTP2C8 } \\
\hline 1 & CAATTGGCTGGAGGAACATAA & GGCTTCAATGGAACCTTTTG & 156 \\
\hline 2 & TAGGGCTCTGTTTTCCATCC & TTGCTGCTATTTGCATTTCC & 212 \\
\hline 3 & TТТСТСССТСАСААССТТGC & TGCTTCAAАТСТСССТССАС & 200 \\
\hline 4 & АААССАAGTCТТСССТАСААСС & TTTTTGGACACATGGGGAAT & 250 \\
\hline 5 & CGATGAATCACAAAATGGACA & АTTTCAATCAGGGCTTGGTG & 209 \\
\hline 6 & GTGGAGGATACTGGCACCAT & TGTCCAGTATCTCTTTTGGCTAAC & 264 \\
\hline 7 & GTTGGAACCAAACCAGCACT & GGCCATGAATTGCTATGACA & 268 \\
\hline 8 & CCAGAGGAGGTGCCATGTAA & GCGCTACGTGATGTCCACTA & 256 \\
\hline $9-1$ & TGGGAAGATTTGATGAGAGG & TGCATATTCTGTTTGTGCAAGTC & 340 \\
\hline $9-2$ & TGAACCAGCAATTAATAACACTTTTT & TGAAGAATGCTAGCCCATCTG & 320 \\
\hline \multicolumn{4}{|l|}{ CYP3A4 } \\
\hline 1 & AAGGGAAAGAGAGGCCTGAT & AAAGCTCCATGCACATAGCC & 173 \\
\hline 2 & CCCCTGAGGAGAAGCATTTT & TCGTTCTCTTGAGCATTCCA & 210 \\
\hline 3 & TGTGCAGTGGGGTAAACTCA & СССТТТТСАААТАССТССТСТG & 220 \\
\hline 4 & TTTCAACACATGAATGCTTACCC & TGTGTATTGTACAACTAAGGGATTATG & 182 \\
\hline 5 & ACACTGGGCATCTGGGATAA & CAGTGGACTACССCTTGGAA & 250 \\
\hline 6 & TTACCACAGCCCТССТTTTG & GCCATGTCCTTCTGGGACTA & 220 \\
\hline 7 & ATGTGGGTTTCCTGTTGCAT & AAAGCAGTTATTTTTAAGAGAGCAAGA & 200 \\
\hline 8 & TGAGCAGTCTTCATGTTAAAAGC & GAAGGAATGGCTTCCAGTTG & 304 \\
\hline 9 & AGATCAAGGACCACGCTTGT & GCATGCCTCTAGAAAGTGCC & 220 \\
\hline 10 & TTTTTCTTTTCAGAGCCTTCC & AGGGATTTGAGGGCTTCACT & 340 \\
\hline 11 & GGCAGAATATGCTTGAACCAG & TCTCTGGAGCTCCTAATACTTCA & 300 \\
\hline 12 & TTTGGCCCAGAGAACAAATTA & AATGACCAGCCCACAAAAGT & 320 \\
\hline 13 & ССТССТCACACTGATTTGGTC & GTCCССТCAАCACTGAAGGA & 350 \\
\hline \multicolumn{4}{|l|}{ OATP2 } \\
\hline $1-1$ & AGAGCTTCATTTTTGAGACTTGA & CTTGTTGCAGTTGCTGTAGGA & 260 \\
\hline $1-2$ & TGTTCTTTTTAACAACTTGCTTTTC & TTCATGTAATCTGGTGTGTGATTC & 400 \\
\hline 2 & TTTTTAACTTTGCAAGTTTGGTT & TGGCTGAGTAGTAGTACCTGGTAAA & 266 \\
\hline 3 & TGGGTATCTTCTCAAAAGGTAACTG & TCAATGAGTGGTCTAATGTAGGTGA & 250 \\
\hline 4 & TGTTGTTAATGGGCGAACTG & GGGGAAGATAATGGTGCAAA & 294 \\
\hline 5 & CCAAGAATGCATGGTTCTTATTC & TGTCAAAGTTTGCAAAGTGAA & 320 \\
\hline 6 & GGAGCTGGATTTTATATTTATTCTGA & TTGTATGATCACTTTCCCTTTGTC & 260 \\
\hline 7 & GCAAAAGAAAGCCAACTCCA & TCATACCATTATTTCССТGAACC & 320 \\
\hline 8 & GAGCAATAGTGACATCACAAGTTTTA & CAGGCTATTCTCACTCTTTGTGTT & 370 \\
\hline 9 & TTTAGTTAAAATTGTTTTCTGCCTTA & TTGAATAAATTTGATTGACATACATTG & 270 \\
\hline 10 & САТСАСАСССАТСАСААТААСА & GGCAAAGATGGAGAGCGTAA & 400 \\
\hline 11 & CAGCCTTGAGAGTTCATAGTAATTTT & AGTTTGAACAAGTGAGACTTCACTAAA & 320 \\
\hline 12 & TCGAATTCTCCTTTAGGTCCA & TGAAATCATGATGCATTGAATAAA & 250 \\
\hline 13 & TGACATGAGGAGAGTTTTGGAA & TCAATGTGGAATATCATGCAGTT & 330 \\
\hline $14-1$ & TGGATCATATAGTCTAACCTTAACCAC & GGATCTGGATACTGGAGAAAATG & 430 \\
\hline $14-2$ & TGGAATGTCTTTATTTCTTCCACA & GTTTCCAAACAGCATTGCAT & 460 \\
\hline
\end{tabular}

${ }^{\text {a }}$ These primers were designed with gene arrangement of complementary DNA expect CYP2C8 exon 3 and CYP3A4 exons 5, 7, and 9 


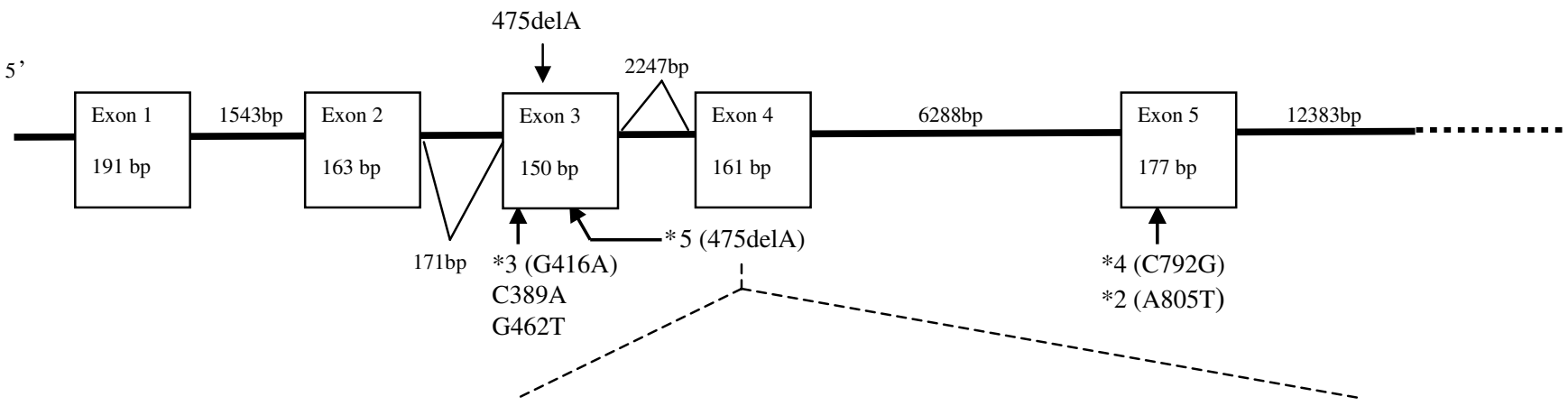

GAGGAGTTGAGAAAAACCAAGGCTTCACCCTGTGATCCCACTTTCATCCTGGGCTGTGCTCCCTGCAATGTGATCTGC Glu Glu Leu Arg Lys Thr Lys Ala Ser Pro Cys Asp Pro Thr Phe Ile Leu Gly Cys Ala Pro Cys Asn Val Ile Cys Glu Glu Leu Arg Lys Pro Arg Leu His Pro Val Ile Pro Leu Ser Ser Trp Ala Val Leu Pro Ala Met Stop

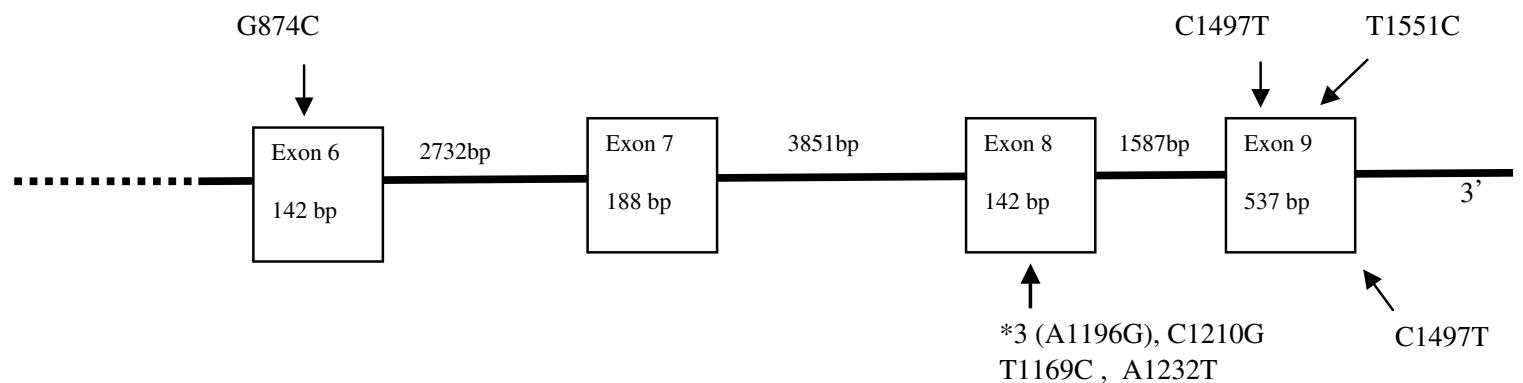

Fig. 1 Schematic drawing of the CYP2C 8 gene and variant sites. $\uparrow$ : Exonic nucleotide substitutions reported by others. $\downarrow$ : Exonic nucleotide substitutions indicated in this study. 475delA was shown in underlined bold and subsequent truncated peptide sequence was depicted underneath the nucleotide sequence

CYP2C8, comprising nine exons, was screened for molecular variant as shown in Fig. 1. The direct sequencing of the patient DNA demonstrated three

Fig. 2 The nucleotide sequencing of CYP2C8 in the patient, her children, and a control (a-c). A-1, A-2, A-3, and B denote the patient, her son, her daughter, and the control, respectivly. Arrows indicate the nucleotide positions of the variant

(a)

475 delA

A-1

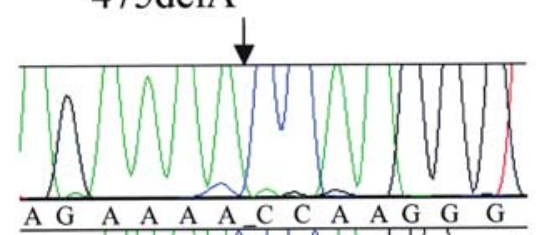

A-2

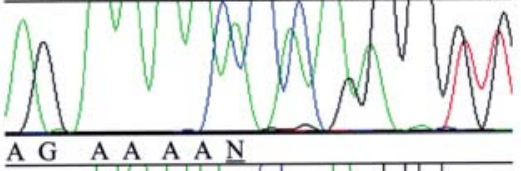

A-3

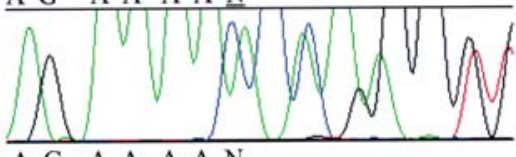

B

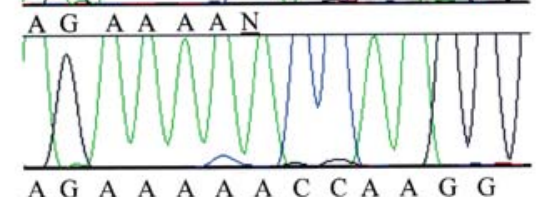

(b) $\mathrm{G} 874 \mathrm{C}$

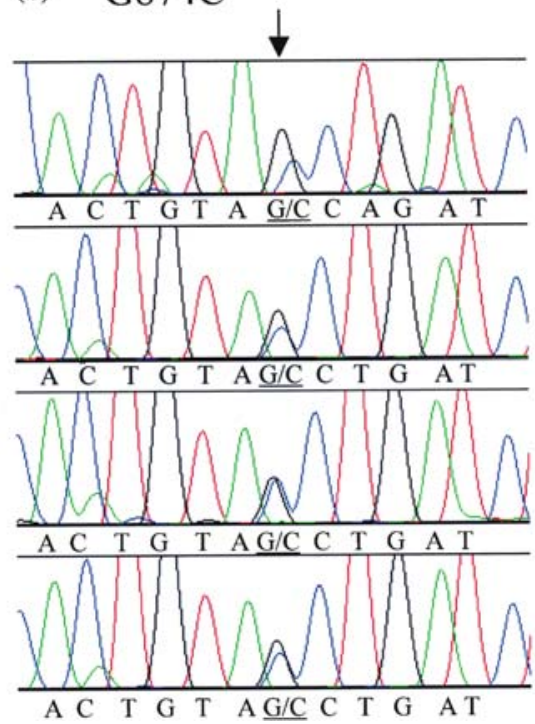

(C) $\mathrm{T} 1551 \mathrm{C}$

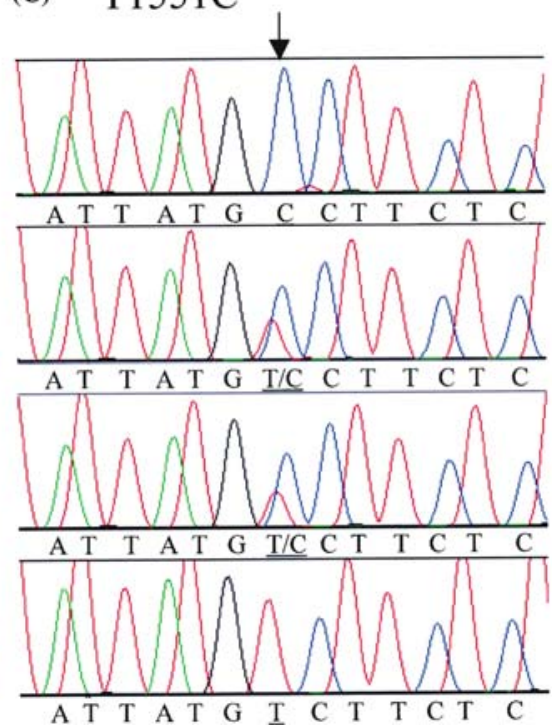

(Figs. 1, 2). The patient was homozygous for the 475delA and T1551C mutations that were identified in the coding region. Deletion of adenine at nucleotide 475 resulted in premature termination at the amino acid residue 177 due to creating an early stop codon. Nakajima et al. (2003) reported that the 475delA mutation, denoting CYP2C $8 * 5 a$, was detected in one subject after screening 200 subjects, showing that the allele frequency of the variant was estimated to be 0.0025 . We screened 384 Japanese subjects for the variant; however, we failed to detect the $475 \mathrm{del}$ A mutation in our sample set. 
Consanguinity, as evident from the clinical record, might explain the homozygous state of the patient. DNA samples obtained from the patient's son and daughter were also examined by direct sequencing; both were heterozygous for the 475delA mutation (Fig. 2a). $\mathrm{C} 1551 \mathrm{~T}$ and G874T variants were newly identified in this study. The patient was homozygous for C1551T variant, and her children were both heterozygous for the variant (Fig. 2c). The patient and her children were heterozygous for G874T in exon 6 (Fig. 2b), and the nucleotide change resulted in $\mathrm{Ala}^{292}$ to $\mathrm{Pro}^{292}$. The nonsynonymous G874T variant appears to be common in the general population because seven Japanese individuals examined were all heterozygous.

All 14 exons of OATP2 were screened, and three nucleotide variations, A388G in exon 4, and C571T and C597T in exon 5, were identified; however, all variants were silent and were also observed in control individuals. CYP3A4 consists of 13 exons (Lamba et al. 2002) and the patient did not show nucleotide variations.

CYP2C8 is a pivotal enzyme in the catalyzing pathway of cerivastatin that is also highlighted by the recent report showing that the drug gemfibrozil, when interacting with cerivastatin, inhibits CYP2C8 activity in human liver microsome (Wang et al. 2002). The patient most likely lacks the enzyme activity of CYP2C 8 due to the homozygous mutation of $475 \mathrm{delA}$ that loses $64 \%$ of the protein structure. Indeed, our patient showed an elevated level of M-1 and a decreased level of M-23 that would be caused by the deficiency of CYP2C8 activity (Ozaki et al. manuscript in preparation). Therefore, the lack of enzyme activity of CYP2C8 might plausibly explain the etiology of cerivastatin-induced rhabdomyolysis. Because the allele frequency of the mutation is extremely low $(<0.0000068$ in our set), the homozygous individuals should be very rare and might experience little clinical impact despite the severity of the rhabdomyolysis. However, a possibility remains that the heterozygous subject is susceptible to the administration of cerivastatin, leading to rather mild myopathy. This possibility could not be answered easily because the drug was withdrawn from the market. As CYP2C8 plays important roles in metabolizing therapeutic drugs such as paclitaxel, an anticancer drug (Rahman et al. 1994); troglitazone, an antidiabetes drug (Yamazaki et al.
2000); and amiodarone, an antiarrhythmic drug (Ohyama et al. 2000); attention should be paid when heterozygous subjects take those drugs.

Acknowledgements This work has been supported by CREST of Japan Science and Technology (II). We thank Miho Kakihara and Yoshiko Miwa for their technical assistance.

\section{References}

Farmer JA (2001) Learning from the cerivastatin experience. Lancet 358:1383-1385

Lamba J, Lin Y, Thummel K, Daly A, Watkins P, Strom S, Zhang J, Schuetz E (2002) Common allelic variants of cytochrome P4503A4 and their prevalence in different populations. Pharmacogenetics 12:121-132

Matushima S, Maeda K, Shitara Y, Sasaki M, Suzuki H, Sugiyama Y (2002) Estimation of a double-transfectanted MDCK II monolayer co-expressing human OATP2 and MRP2. Jpn Pharmacol Ther 30:S441-S444

Mück W (2000) Clinical pharmacokinetics of cerivastatin. Clin Pharmacokinet 39:99-116

Nakajima M, Fujiki Y, Noda K, Ohtsuka H, Ohkuni H, Kyo S, Inoue M, Kuroiwa Y, Yokoi T (2003) Genetic polymorphisms of CYP2C8 in Japanese population. Drug Metab Dispos 31:687-690

Ohyama K, Nakajima M, Suzuki M, Shimada N, Yamazaki H, Yokoi T (2000) Inhibitory effect of amiodarone and its $N$ deethylated metabolite on human cytochrome P450 activities: prediction of in vivo drug interactions. Clin Pharmacol 49:244 253

Rahman A, Korzekwa KR, Grogan J, Gonzalez FJ, Harris JW (1994) Selective biotransformation of taxol to 6 alpha-hydroxytaxol by human cytochrome P450 2C8. Cancer Res 54:5543-5546

Rossenson R (2004) Current overview of statin-induced myopathy. Am J Med 116:408-416

Staffa J, Chang J, Green L (2002) Cerivastatin and reports of fatal rhabdomyolysis. N Engl J Med 346:539-540

Stein E (1998) Cerivastatin in primary hyperlipidemia: a multicenter analysis of efficacy and safety. Am J Cardiol $82: 40 \mathrm{~J}-46 \mathrm{~J}$

Wang J-S, Neuvonen M, Wen Z, Backman JT, Neuvonen PJ (2002) Gemfibrozil inhibits CYC2C8-mediated cerivastatin metabolism in human liver microsomes. Drug Metab Dispos 30:1352-1356

Yamazaki H, Suzuki M, Shimada N, Nakajima M, Yokoi T (2000) In vitro effects of troglitazone and its metabolites on drug oxidation activities of human cytochrome P450 enzymes: comparison with pioglitazone and rosiglitazone. Xenobiotica 30:61-70 